\title{
CONTRIBUIÇÕES NATURAIS E ANTROPOGÊNICAS PARA A CONCENTRAÇÃO E DISTRIBUIÇÃO DE METAIS PESADOS EM SEDIMENTO DE CORRENTE NO RIO DO FORMOSO, MUNICÍPIO DE BURITIZEIRO - MG.
}

\author{
Baggio, Hernando ${ }^{1} \&$ Horn, Heinrich Adolf ${ }^{2}$
}

\begin{abstract}
RESUMO
O Rio do Formoso é um importante tributário do Rio São Francisco no noroeste do estado de Minas Gerais. Sua bacia encontra-se inserida no Bioma Cerrado, suas águas drenam imensos latifúndios com forte tendência agropecuária, influenciando diretamente nas características fisico-químicas e químicas da água superficial e do sedimento de corrente. Foram coletadas 11 amostras de sedimentos, nos quais foram determinadas as concentrações de $\mathrm{Cu}, \mathrm{Cd}, \mathrm{Cr}, \mathrm{Ni}, \mathrm{Pb}, \mathrm{Zn}$ por ICP-OES, com, extração parcial ácida. Os resultados foram comparados à resolução CONAMA 344/2004. A caracterização mineral foi obtida por difratometria de Raios-X, e a composição geoquímica dos litotipos foi determinada por ICP-OES. Os teores totais dos metais $\mathrm{Cd}$ e Cr nos sedimentos violaram os valores de referência estabelecidos pela Resolução CONAMA 344/2004. A disponibilidade desses metais nos sedimentos é resultado direto dos resíduos metalorgânicos gerados pela agricultura comercial. A assinatura geoquímica para o elemento cromo presente no sedimento, confirma a contribuição natural geológica. O mineral predominante é o quartzo, a presença de minerais de argila, sugere uma maior ou menor troca de elementos do sedimento para a coluna de água.
\end{abstract}

\begin{abstract}
The Formoso River is an important tributary of the São Francisco River in the northwest of Minas Gerais State. Its basin is inserted in the Cerrado Biome, where its waters drain large agropecuary landed estates, what directly influences the physicochemical characteristics of superficial waters and stream sediments. The $\mathrm{Cu}, \mathrm{Cd}, \mathrm{Cr}, \mathrm{Ni}, \mathrm{Pb}$ and $\mathrm{Zn}$ parameters were analyzed in 11 sediment samples by using the chemical partial acid extraction technique and ICP-OES reading, and the results were compared to the CONAMA resolution 344/2004. Mineral characterization was accomplished by X-Ray diffractometry and geochemical lithotypes analysis was made by ICP-OES. It revealed that the levels of $\mathrm{Cd}$ and $\mathrm{Cr}$ are above the levels recommended by the resolution CONAMA 344/2004. The presence of these metals in sediments results directly of the metal-organic residues generated by commercial agriculture. The geochemistry signature for the $\mathrm{Cr}$ element present in the sediment confirms the geological natural contribution. Quartz is the predominant mineral; the presence of clay minerals suggests a greater or minor interchange of elements from the sediment to the water column.
\end{abstract}

Key words: Heavy metals, stream sediments, natural, anthropogenic, orienting values.

\section{INTRODUÇÃO}

A dinâmica da evolução dos sistemas produtivos e o domínio sobre a tecnologia têm como conseqüência uma ampla problemática ambiental onde o meio ambiente físico e biológico se instala no cenário principal desses processos.

A região investigada vem sendo utilizada para fins agrícolas, desde a década de 60 , por imensos latifúndios que introduziram a monocultura de pinus e eucaliptos. Contudo, com a chegada dos grandes grupos capitalistas agrícolas, trazendo consigo novas agrotecnologias, a produção diversificou-se e ganhou caráter comercial. Os grãos, em especial a soja, milho, feijão, café e, atualmente, a monocultura de algodão, desenharam uma nova paisagem agrícola na região.

Segundo Alloway \& Ayres (1997), a agricultura é uma das maiores fontes não pontuais de poluição por metais pesados, sendo as fontes principais as impurezas em fertilizantes ( $\mathrm{Cd}, \mathrm{Cr}, \mathrm{Mo}, \mathrm{Pb}, \mathrm{U}, \mathrm{V}, \mathrm{Zn}$ ); os pesticidas $(\mathrm{Cu}, \mathrm{As}, \mathrm{Hg}, \mathrm{Pb}, \mathrm{Mn}, \mathrm{Zn}$ ); os preservativos de madeiras
(As, $\mathrm{Cu}, \mathrm{Cr}$ ) e os dejetos de produção de aves e porcos $(\mathrm{Cu}, \mathrm{Zn})$.

A área objeto desta pesquisa é incipiente no que diz respeito a trabalhos científicos sistemáticos, trabalhos de ordem pontual vêm sendo desenvolvidos na região. Uma das primeiras investigações objetivando a obtenção de dados químicos da água e sedimentos do Rio São Francisco, foram feitos pelo o Centro Tecnológico de Minas Gerais (CETEC) e o Conselho de Meio Ambiente de Minas Gerais - COPAM (CETEC, 1980; COPAM, 1986); entre os anos de1990 a 1992, alunos de mestrado da Fachhochschule München Alemanha, sob a orientação do Prof. Dr. A. H. Horn e do Prof. Dr. W. Jantsch investigaram os teores de metais pesados nos sedimento de corrente e fundo no RSF, entre a represa Três Marias e o Córrego Consciência; Mozeto (2003) elaborou um diagnóstico sobre a contaminação ambiental por metais pesados na água e sedimentos na Represa de Três Marias - MG; Oliveira (2007) pesquisou a presença de metais pesados nos sedimentos no entrono da barragem de Três Marias e 
no Rio São Francisco; Viana (2006) apresentou uma pesquisa que buscou avaliar a condição geoquímica ambiental das veredas na Bacia Hidrográfica do Rio do Formoso; Ribeiro (2007) avaliou os níveis de contaminação por metais pesados nas águas superficiais do Rio São Francisco em Pirapora e sua relação com as atividades industriais; Braga (2007) em sua dissertação de Mestrado, investigou a contaminação do solo por metais pesados em pilhas de rejeitos antigas e atuais das indústrias de Fe-Si na região de Várzea da Palma-MG; Baggio (2008) pesquisou a presença de metais pesados nas águas superficiais e nos sedimentos de corrente do Rio do Formoso-MG.

Os objetivos deste estudo foram: (I) avaliar a concentração total e a distribuição dos elementos: $\mathrm{Cu}, \mathrm{Cd}, \mathrm{Cr}, \mathrm{Ni}, \mathrm{Pb}$ e $\mathrm{Zn}$, baseados nos parâmetros de toxicidade potencial para o homem e a biota aquática; (II) verificar a origem natural ou antropogênica desses elementos; (III) quantificar e comparar com valores orientadores adotados pela Resolução CONAMA n ${ }^{\circ}$ 344/2004 e (IV) caracterizar fisicamente os sedimentos de corrente.

A área da pesquisa encontra-se regionalmente inserida na bacia hidrográfica do Rio São Francisco, mais especificamente no segmento Alto/médio curso, sendo a sub-bacia do Rio do Formoso a área efetiva da pesquisa, como pode ser visto no mapa da (Figura 1).

\section{ASPECTOS FISIOGRÁFICOS CARACTERÍSTICAS GEOLÓGICAS}

A bacia do Rio do Formoso encontra-se localizada na porção meridional da Bacia Sanfranciscana, dentro dos limites do Cráton do São Francisco, mais especificamente na bacia cretácea do oeste mineiro.

Segundo Sgarbi (1989) a Bacia Sanfranciscana representa um dos mais expressivos exemplos da sedimentação continental fanerozóica do país. Seu preenchimento é relacionado com o último megaciclo geodinâmico que afetou a bacia intracratônica neoproterozóica do São Francisco após a sedimentação dos grupos Macaúbas, Paranoá e Bambuí. A coluna litoestratigráfica esquemática da área (Figura 2) visualiza o contexto geológico, litológico, sedimentológico e paleoambiental das Unidades Geológicas representativas, constituídas pelos principais Grupos e suas respectivas Formações.

\section{CARACTERÍSTICAS GEOMORFOLÓGICAS}

A área da pesquisa encontra-se diretamente influenciada pelo contexto geológico-geomorfológico regional, marcada de forma geral por um plano ligeiramente ondulado, correspondendo à Superfície Sul-Americana I e II (Valadão, 1998). Apresenta-se

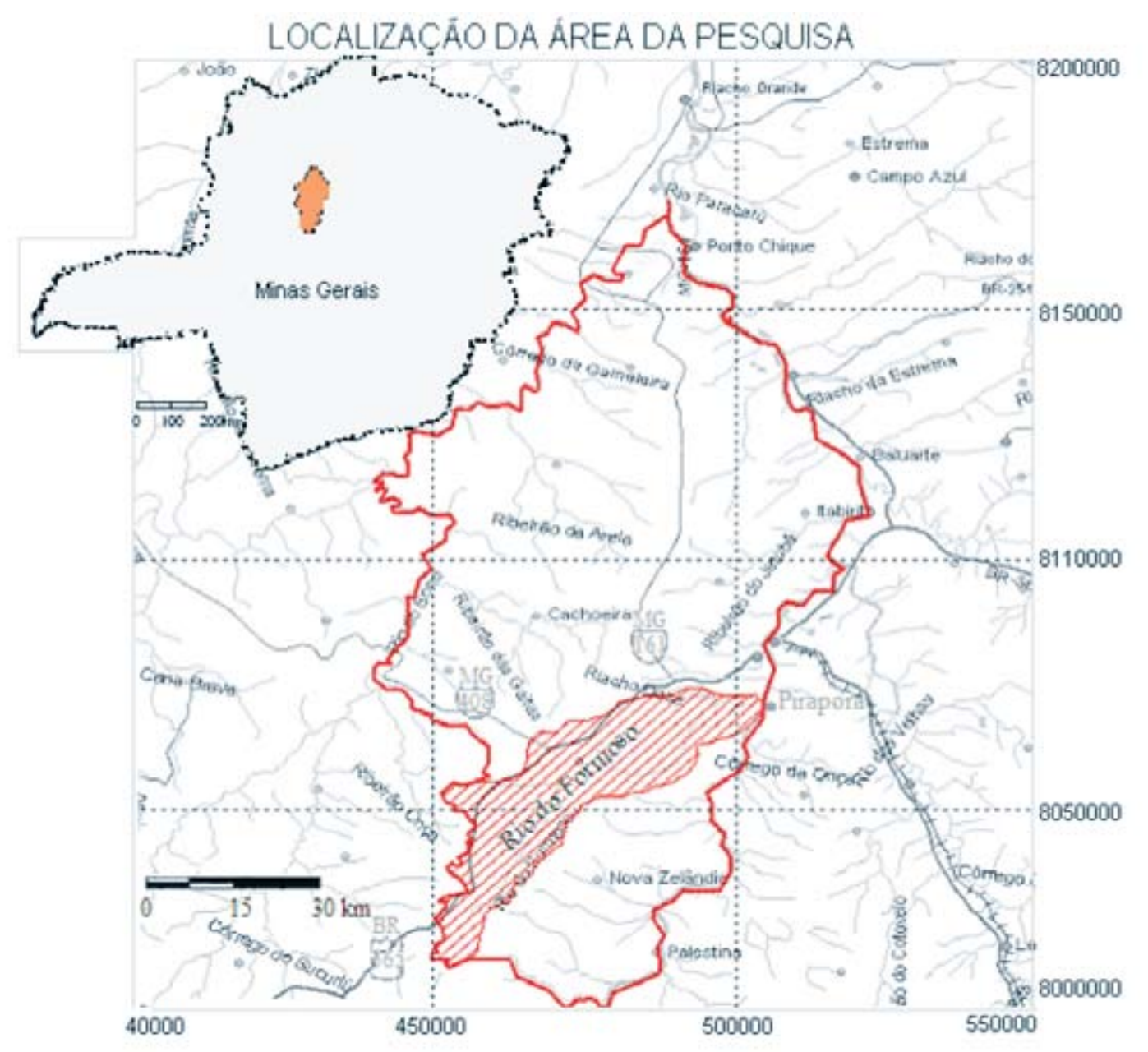

Figura 1- Localização geral da área da pesquisa no contexto geográfico municipal. 


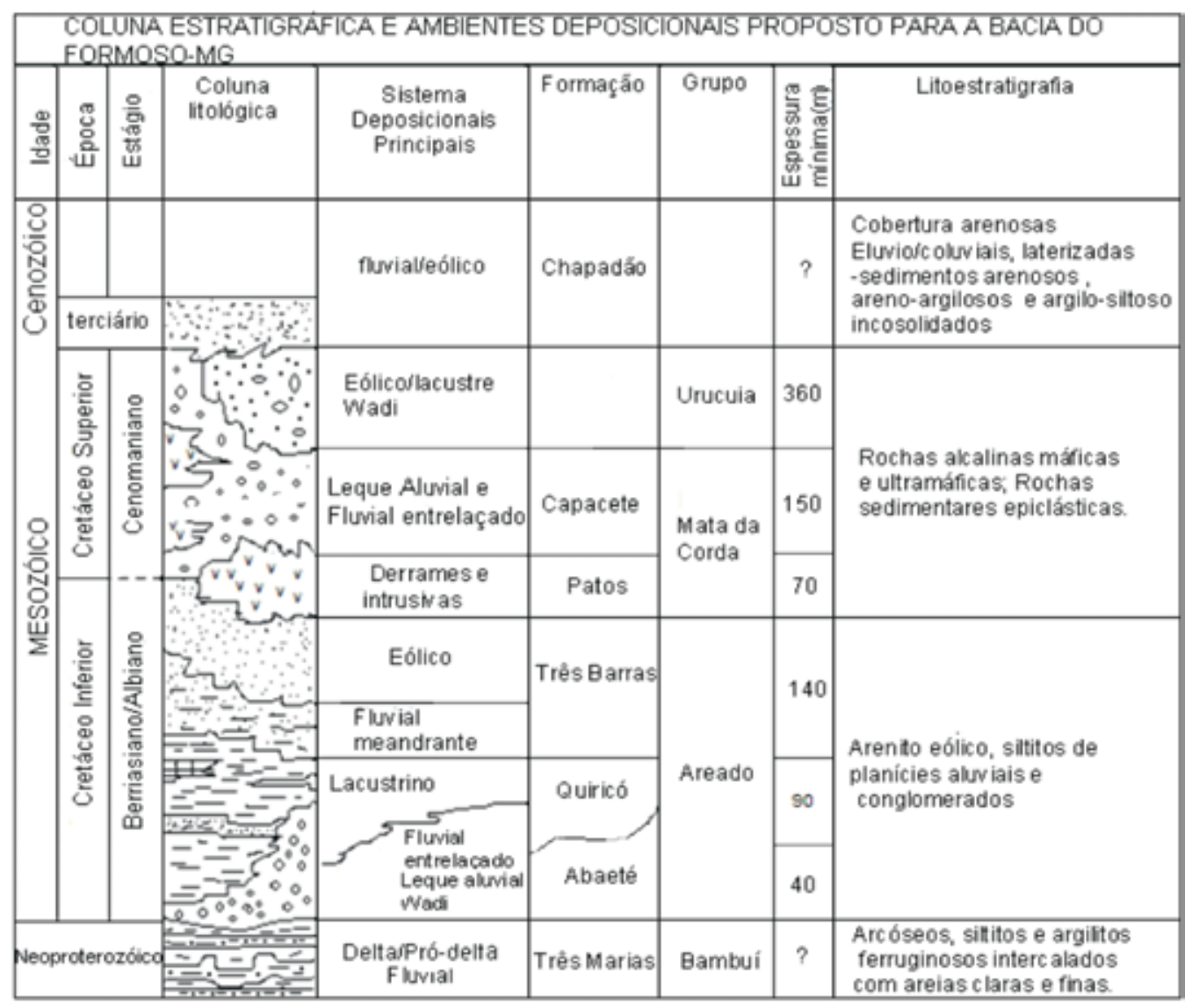

Figura 2 - Coluna litoestratigráfica esquemática proposta para a área da pesquisa. (Modificado de Seer et al.,1989).

a seguir a descrição dos principais compartimentos geomorfológicos encontrados na área da pesquisa: 1) A Superfície Tabular - Unidades de Chapadas constituise num conjunto de áreas aplainadas do Terciário, de expressiva espacialização geográfica, localizado no denominado Chapadão dos Gerais; 2) Unidades de Colinas - são originadas a partir do escoamento superficial concentrado, esculpidas sobre os litotipos do Cretáceo Superior, Inferior e do Neoproterozóico e ocupam uma área geográfica razoável dentro da bacia; 3) Planície aluvial Unidades de vales e Terraços Quaternários. Estas duas unidades geomórficas localizam-se na porção terminal da bacia - baixo curso do Rio do Formoso. As condições morfodinâmicas encontradas na bacia hidrográfica indicam certa relação entre a espacialização geográfica dos metais e os compartimentos geomórficos, estando estes últimos, influenciados pelos processos de erosão, transporte e deposição (Baggio, 2008).

\section{CARACTERÍSTICAS HIDROGRÁFICAS}

Geograficamente, a sub-bacia do Rio do Formoso posiciona-se na porção sudoeste do município de Buritizeiro, drenando uma área de $826 \mathrm{~km}^{2} \mathrm{e}$, se integrando à bacia hidrográfica do rio São Francisco pela margem direita. O Rio do Formoso pode ser classificado como um canal aberto e, seu fluxo principal é do tipo turbulento de corrente e encachoeirado. A tipologia do canal fluvial do rio pode ser definida como um curso de canais únicos, podendo ser subdividido principalmente em canais retos e sinuosos, sendo os canais meandrantes expressivos. As formas topográficas do canal principal e dos canais secundários apresentam-se como leitos com segmentos rochosos e leitos com segmentos aluviais, estes favorecendo a mobilidade dos sedimentos. A dinâmica da bacia é responsável pela sedimentação fluvial, que inclui os processos de remoção, transporte e sedimentação das partículas. Alguns aspectos da sedimentação fluvial, que ocorrem principalmente nos segmentos alto e baixo curso, encontram-se relacionados à remoção intensa de detritos das vertentes, cuja causa principal é a utilização das terras agrícolas. Outro fator que promove o aumento das taxas de sedimentação é a abertura de estradas vicinais. A distribuição e dispersão dos metais pesados ao longo do perfil longitudinal podem estar correlacionadas às características litoestruturais, geomorfológicas e à morfodinâmica atuantes na bacia de drenagem (Baggio, 2008).

\section{CARACTERÍSTICAS PEDOLÓGICAS}

Dentro de um quadro litogeomórfico definido para a bacia do Rio Formoso, desenvolveu-se uma cobertura pedológica diferenciada, devido às influências do material de origem e do relevo. Apresenta-se a seguir as principais classes de solos definidas para 
a bacia: Latossolos Vermelho-Amarelos, profundos, distróficos álicos e de textura argilosa em associação com Latossolo Vermelho-Escuro álico de textura argilosa; Neossolos Quartzarênicos; Gleissolo pouco húmico álico, geralmente associado aos subsistemas de veredas; Neossolos distróficos álicos e os Neossolos Flúvicos eutróficos. As interferências antropogênicas, como a retirada da cobertura vegetal, construção de estradas e plantio de monoculturas, expõem os solos aos processos erosivos, sendo eles carreados pelas águas e/ou vento em direção aos cursos de água; os resíduos metalorgânicos gerados nas áreas agricultáveis e incorporados aos solos estão comprometendo os recursos hídricos (Baggio, 2008).

\section{USO E OCUPAÇÃO DO SOLO}

O estímulo à ocupação recente dos cerrados brasileiros é resultante das políticas governamentais destinadas à modernização do setor agropecuário nacional, adquirindo novos incentivos para seu crescimento a partir da segunda metade da década de 60. Nessa década, grande parte das terras drenadas pelo Rio do Formoso foi também destinada à implantação de monoculturas de eucalipto e pinus. As atividades monocultoras são ampliadas a partir da década de 90, com a introdução das culturas comerciais de soja, milho, feijão e, posteriormente, o café - momento em que as áreas mais próximas às drenagens são ocupadas, ampliando o impacto sobre a vegetação nativa e veredas, seja pelo impacto indireto, devido à acentuação dos processos erosivos e assoreamento, como também pela construção de barramentos destinados à irrigação (Baggio, 2008).

\section{METODOLOGIA}

A seleção dos pontos de amostragem na bacia de drenagem do Rio do Formoso considerou as variações na paisagem que refletissem os diferentes tipos de unidades litológicas, compartimentos geomórficos e suas áreas de transição, como mostra a (Figura 3). Para o tratamento dos dados obtidos, foi utilizado o programa GTM-PRO 4.2. A base cartográfica dos mapas foi elaborada através da interpolação de curvas de imagens Geotiff obtidas pela The Shuttle Radar Topography Mission (SRTM) na escala 1/250000 - Datun WGS 84 e distribuídas pela National Aeronautics and Space Administration (NASA). O software SPRING 3.4 foi utilizado para obtenção dos cenários naturais. $\mathrm{O}$ editor gráfico Surfer 8, da Golden, foi utilizado para a edição final das Figuras utilizadas durante o desenvolvimento do trabalho.

As coletas foram realizadas em duas campanhas de campo, sendo a primeira realizada na estação úmida (março/2007) e a segunda na estação seca (julho/2007), com a finalidade de avaliar a influência climática. Coletou-se um total de onze amostras (por campanha de campo) de sedimentos, com cerca de $1,5 \mathrm{~kg}$ cada, a uma profundidade até $35 \mathrm{~cm}$ da lâmina de água, foram coletadas amostras nas duas margens do rio, afastada $30 \mathrm{~cm}$ do leito menor e também, sobre rochas no leito. Em laboratório, as amostras foram secas à temperatura ambiente, preparadas, pesadas e fracionadas em peneira de aço até a fração $<0,063 \mathrm{~mm}$, a mais adequada para a determinação dos metais pesados. A abertura das amostras foi feita através de digestão ácida (água-régia). A leitura dos metais foi feita por Espectrômetro de Emissão Óptica com Plasma Indutivamente Acoplado de Argônio - ICP-OES, modelo M 4165 - Epectroflame - Spectro do (CPMTC/UFMG).

As amostras de rochas foram coletadas nos afloramentos de rochas frescas ou pouco alteradas. Coletou-se $2 \mathrm{~kg}$ de rochas de forma a representar os vários litotipos existentes na área. Em laboratório, as amostras foram secadas a uma temperatura de $90^{\circ} \mathrm{C}$, britadas a $2 \mathrm{~mm}$, quarteadas e homogeneizadas; a pulverização foi feita em moinho de aço a 95\% - 150 mesh. A abertura química foi realizada através de digestão ácida e a determinação dos elementos ocorreu através do ICP-OES, do (CPMTC/UFMG).

A análise mineralógica dos sedimentos foi realizada no laboratório do CDTN/CNEN, o método utilizado foi difração de Raios-X - método do pó. A leitura das amostras foi feita através do difratômetro Rigaku, modelo D/Max-2B. Os resultados dos difratogramas foram tratados pelo programa Jade for Windows XRD Pattern Processingand Indentification version 3.0.

As cores nos sedimentos foram descritas em campo, para a determinação das cores foi utilizada a Munsell Soil Color Charts (2000).

\section{RESULTADOS DAS ANÁLISES CARACTERÍSTICAS DOS SEDIMENTOS}

Os sedimentos coletados nos onze pontos de amostragem, ao longo do perfil longitudinal, apresentaram particularidades físicas e químicas relativas ao seu local de coleta, em razão da litologia, pedologia, compartimento geomórfico e uso do solo.

\section{FRAÇÃO GRANULOMÉTRICA}

A fração granulométrica utilizada para a determinação dos metais pesados e, para a determinação mineralógica, foi à fração $<0,063 \mathrm{~mm}$, a mais adequada para a determinação dos metais pesados.

\section{COR DOS SEDIMENTOS}

As cores dos sedimentos, nos pontos amostrados, mantiveram uma tendência entre $2.5 \mathrm{YR}$ e $5 \mathrm{YR}$ - tons que vão do amarelo/avermelhado ao amarelo. As cores encontram-se relacionadas aos hidróxidos de ferro $\mathrm{Fe}(\mathrm{OH})$, principalmente à goethita $\mathrm{FeO}(\mathrm{OH})$, hematita $\mathrm{Fe}_{2} \mathrm{O}_{3}$ e à magnetita $\mathrm{Fe}_{3} \mathrm{O}_{4}$; encontradas nos principais litotipos presentes na área e nas principais classes de solos. 


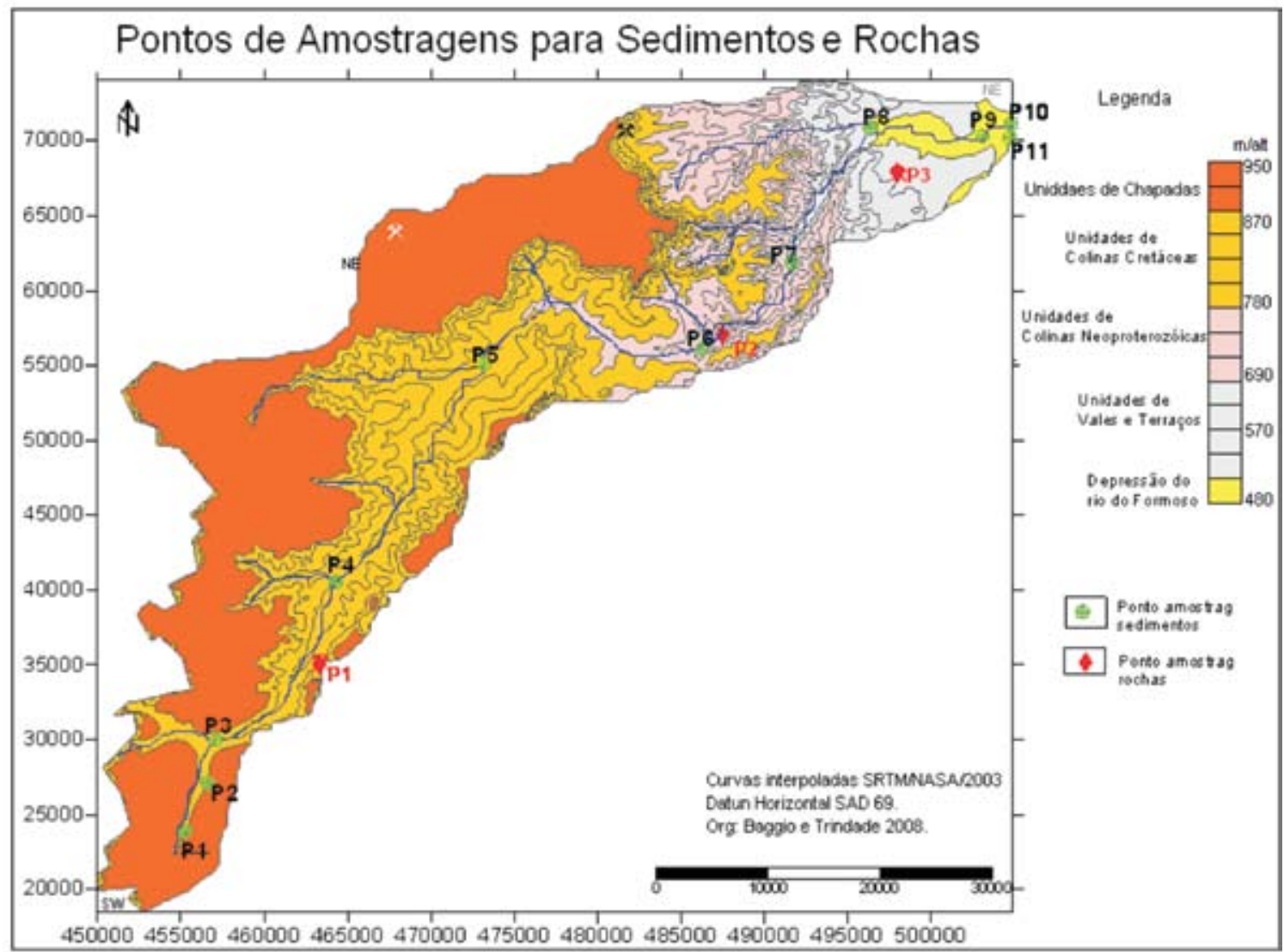

Figura 3 - Mapa com os pontos de amostragem para sedimentos de corrente e rochas, apresentado também, os compartimentos geomórficos definidos para a área.

\section{COMPOSIÇÃO MINERALÓGICA}

A composição mineralógica dos sedimentos é constituída pelo grupo dos seguintes minerais terrígenos: (Quartzo $>60 \%$ ), minerais de argila (caolinita entre 3\% a $20 \%$ ), mica-grossa (moscovita $<3 \%$ ), feldspatos (microclina $3 \%$ a $5 \%$ ), minerais acessórios pesados (anatásio, goethita, hematita e magnetita entre 3\% a 5\%) e minerais químicos e autigênicos representados pelos sulfatos (gipsita 3\% a 20\%), como mostra a (Tabela 1). $\mathrm{Na}$ fração fina $<100$ (mesh), houve uma predominância em porcentagem do $\mathrm{SiO}_{2}$, seguido do $\mathrm{Al}, \mathrm{Fe}, \mathrm{TiO}_{2}$ e elementos menores. $\mathrm{O}$ quartzo $\left(\mathrm{SiO}_{2}\right)$ foi o mineral com maior predominância em todas as mostras, sua ocorrência pode estar associada ao retrabalhamento dos arenitos do Grupo Areado e Mata da Corda, que compõem a parte superior da coluna estratigráfica e, dos arenitos arcoseanos do Grupo Bambuí - Fm: Três Marias, parte inferior da coluna estratigráfica (Figura 2). $\mathrm{OAl}$, ocorre principalmente da caolinita $\mathrm{Al}_{2} \mathrm{Si}_{2} \mathrm{O}_{5}(\mathrm{OH})_{4}$ e da moscovita $\mathrm{KAl}_{3} \mathrm{Si}_{3} \mathrm{O}_{10}(\mathrm{OH})_{2}$, estando associado, aos arenitos da Fm. Chapadão, Fm. Três Barras e Fm. Três Marias, de grande expressão geográfica na área.

$\mathrm{O} F$, encontra-se sob a forma de goethita $\mathrm{FeO}(\mathrm{OH})$, hematita $\mathrm{Fe}_{2} \mathrm{O}_{3}$ e magnetita $\mathrm{Fe}_{3} \mathrm{O}_{4}$, sua origem encontrase associada aos litotipos do Grupo Areado e Mata da Corda e aos litotipos da Fm. Três Marias, que compõem o substrato rochoso da bacia. O anatásio $\mathrm{TiO}_{2}$ está associado à presença de brechas lapilíticas limitadas por tufos maciços do Grupo Mata da Corda, e por fim, os elementos menores presentes nos litotipos.

\section{ANÁLISE GEOQUÍMICA DOS LITOTIPOS}

A análise dos dados apresentados na (Tabela 2) mostra que, o teor do elemento $\mathrm{Cd}$ presente nos litotipos Arenitos e Argilitos encontra-se abaixo dos valores de referência, portanto, não há enriquecimento desse metal para os sedimentos. Para o elemento $\mathrm{Cr}$, os teores não ultrapassaram os valores de referência estabelecidos por Bowen (1979) e Krauskopf (1976), para os arenitos, no entanto, para os litotipos argilitos, os valores encontramse muito próximos do limite estabelecido.

\section{ANÁLISE QUÍMICA - METAIS PESADOS}

Estudou-se o comportamento geoquímico dos seguintes elementos: $\mathrm{Cu}, \mathrm{Cr}, \mathrm{Cd}, \mathrm{Ni}, \mathrm{Pb}$ e $\mathrm{Zn}$. Foram obtidas informações sobre o nível de concentração total, a variação dos teores ao longo do perfil longitudinal, a correlação entre a fração granulométrica e com a composição mineralógica obtidas nos sedimentos e, a correlação entre a concentração dos metais e os fatores de ordem antrópica e natural. Finalmente procedeu-se a comparação dos dados com os valores orientadores estabelecidos pela Resolução CONAMA 344/2004. A (Tabela 3) apresenta os valores totais máximos e mínimos, obtidos para os seis metais, em dois períodos 
TABELA 1- COMPOSIÇÃO MINERALÓGICA DAS AMOSTRAS DE SEDIMENTOS

Fonte: Centro de Desenvolvimento da Tecnologia Nuclear (2008).

TABELA 1- COMPOSIÇÃO MINERALÓGICA DAS AMOSTRAS DE SEDIMENTOS

\begin{tabular}{|c|c|c|c|c|}
\hline \multirow[b]{2}{*}{ Amostras/Locais } & \multicolumn{4}{|c|}{ Minerais Identificados \% } \\
\hline & $\begin{array}{c}\text { Predominante } \\
(>60 \%)\end{array}$ & $\begin{array}{c}\text { Maior } \\
(<20 \%)\end{array}$ & $\begin{array}{l}\text { Menor } \\
(<5 \%)\end{array}$ & $\begin{array}{c}\text { Minoritário } \\
(<3 \%)\end{array}$ \\
\hline $\begin{array}{c}\text { Alto curso } \\
P-01 \\
P-02-03\end{array}$ & Quartzo & $\begin{array}{c}\text { Caolinita } \\
\text { Gipsita }\end{array}$ & Anatásio & $\begin{array}{c}\text { Goethita } \\
\text { Hematita } \\
\text { Magnetita }\end{array}$ \\
\hline $\begin{array}{c}\text { Alto/médio } \\
P-04-\mathrm{P}-05\end{array}$ & Quartzo & - & $\begin{array}{l}\text { Caolinita } \\
\text { Microclina }\end{array}$ & $\begin{array}{l}\text { Anatásio } \\
\text { Goethita } \\
\text { Hematita } \\
\text { Magnetita }\end{array}$ \\
\hline $\begin{array}{c}\text { Médio/baixo } \\
P-06-P-07\end{array}$ & Quartzo & - & Caolinita & $\begin{array}{l}\text { Anatásio } \\
\text { Gipsita } \\
\text { Microclina } \\
\text { Magnetita }\end{array}$ \\
\hline $\begin{array}{c}\text { Baixo curso } \\
\text { P - 08 } \\
\text { FF/ FFII / RSF }\end{array}$ & Quartzo & - & $\begin{array}{l}\text { Caolinita } \\
\text { Microclina }\end{array}$ & $\begin{array}{c}\text { Anatásio } \\
\text { Gipsita } \\
\text { Moscovita } \\
\text { Magnetita }\end{array}$ \\
\hline
\end{tabular}

Fonte: Centro de Desenvolvimento da Tecnologia Nuclear (2008).

\section{TABELA 2 - VALORES DE REFERÊNCIA E CONCENTRAÇÃO MÉDIA DE CÁDMIO E CROMO CONTIDOS NOS LITOTIPOS.}

TABELA 2 - VALORES DE REFERÊNCIA E CONCENTRAÇÃO MÉDIA DE CÁDMIO E CROMO CONTIDOS NOS LITOTIPOS.

\begin{tabular}{l|c|c|c}
\hline \multicolumn{3}{c}{ VALORES REFERENCIA - Cd e Cr- LITOTIPOS ARENITOS E FOLHELHOS } \\
\hline $\begin{array}{c}\text { Elemento } \\
\text { Cd }\end{array}$ & $\begin{array}{l}\text { Referência - Bowen, } \\
(1979) \text { e Krauskopf, } \\
(1976) .\end{array}$ & $\begin{array}{c}\text { Concentração } \\
\text { observada }\end{array}$ & $\begin{array}{l}\text { Padrão - litotipos } \\
\text { Rio do Formoso }\end{array}$ \\
\hline Arenitos & $0,05 \mathrm{ppm}$ & $<0,01 \mathrm{ppm}$ & ${ }^{*} \mathrm{NE}$ \\
\hline $\begin{array}{l}\text { Folhelhos. Grupo } \\
\text { Bambui }\end{array}$ & $0,22 \mathrm{ppm}$ & $<0,01 \mathrm{ppm}$ & ${ }^{*} \mathrm{NE}$ \\
\hline
\end{tabular}

\begin{tabular}{l|c|c|c}
\hline \multicolumn{1}{c|}{$\begin{array}{c}\text { Elemento } \\
\mathrm{Cr}\end{array}$} & $\begin{array}{l}\text { Referência: Bowen, } \\
(1979) \text { e Krauskopf, } \\
(1976) .\end{array}$ & $\begin{array}{c}\text { Concentração } \\
\text { observada }\end{array}$ & $\begin{array}{c}\text { Padrão - litotipos } \\
\text { Rio do Formoso }\end{array}$ \\
\hline Arenitos & $35 \mathrm{ppm}$ & $8,288 \mathrm{ppm}$ & ${ }^{\star} \mathrm{NE}$ \\
\hline $\begin{array}{l}\text { Folhelhos. Grupo } \\
\text { Bambui }\end{array}$ & $90 \mathrm{ppm}$ & $89 \mathrm{ppm}$ & $\mathrm{NE}$ \\
\hline
\end{tabular}

*NE: não enriquecimento

climáticos - chuvoso e seco.

São discutidos neste trabalho os aspectos geoquímicos dos metais $\mathrm{Cd}$ e $\mathrm{Cr}$, metais que violaram a Resolução CONAMA 344/2004.

Os valores obtidos para $\mathrm{Cd}$ foram: o mínimo de $0,01 \mathrm{mg} / \mathrm{kg}$ e o máximo de $1,221 \mathrm{mg} / \mathrm{kg}$, na estação chuvosa, e o mínimo $0,001 \mathrm{mg} / \mathrm{kg}$ e máximo 1,126 $\mathrm{mg} / \mathrm{kg}$, na estação seca. Os pontos P1 e P3 violaram em mais de $100 \%$ os valores orientadores estabelecidos pela Resolução CONAMA 344/2004 para TEL, que é de $0,6 \mathrm{mg} / \mathrm{kg}$.
Em relação aos outros pontos, nenhum violou os valores orientadores proposto pela resolução CONAMA. Os valores obtidos foram o mínimo de 0,01 $\mathrm{mg} / \mathrm{kg}$ e o máximo de $1,221 \mathrm{mg} / \mathrm{kg}$, na estação chuvosa, e o mínimo $0,001 \mathrm{mg} / \mathrm{kg}$ e máximo $1,126 \mathrm{mg} / \mathrm{kg}$, na estação seca. $\mathrm{O}$ aumento apresentado nos teores totais de Cd para os sedimentos, principalmente nos pontos P1 e P3, está diretamente associado ao incremento de agroquímicos utilizados no plantio de grãos.

Os teores de Cr foram: mínimo de $0,1539 \mathrm{mg} / \mathrm{kg}$ e máximo de $64,00 \mathrm{mg} / \mathrm{kg}$, na estação chuvosa, e mínimo 

TABELA 3 - VALORES TOTAIS DOS METAIS ANALISADOS - ESTAÇÃO CHUVOSA E
SECA

\begin{tabular}{lccccccccccccc} 
Ponios & $\begin{array}{c}\text { Cobre }(\mathrm{Cu}) \\
\mathrm{mg} / \mathrm{kg}\end{array}$ & \multicolumn{2}{c}{$\begin{array}{c}\text { Cádmio }(\mathrm{Cd}) \\
\mathrm{mg} / \mathrm{kg}\end{array}$} & \multicolumn{2}{c}{$\begin{array}{c}\text { Cromo }(\mathrm{Cr}) \\
\mathrm{mg} / \mathrm{kg}\end{array}$} & $\begin{array}{c}\text { Niquel }(\mathrm{N}) \\
\mathrm{mg} / \mathrm{kg}\end{array}$ & \multicolumn{2}{c}{$\begin{array}{c}\text { Chumbo }(\mathrm{Pb}) \\
\mathrm{mg} / \mathrm{kg}\end{array}$} & \multicolumn{2}{c}{$\begin{array}{c}\text { Zinco(Zn) } \\
\mathrm{mg} / \mathrm{kg}\end{array}$} \\
& $\begin{array}{c}\text { Est. } \\
\text { Chuvosa }\end{array}$ & $\begin{array}{c}\text { Est. } \\
\text { Seca }\end{array}$ & $\begin{array}{c}\text { Est. } \\
\text { Chuvosa }\end{array}$ & $\begin{array}{c}\text { Est. } \\
\text { Seca }\end{array}$ & $\begin{array}{c}\text { Est. } \\
\text { Chuvosa }\end{array}$ & $\begin{array}{c}\text { Est. } \\
\text { Seca }\end{array}$ & $\begin{array}{c}\text { Est. } \\
\text { Chuvosa }\end{array}$ & $\begin{array}{c}\text { Est. } \\
\text { Seca }\end{array}$ & $\begin{array}{c}\text { Est. } \\
\text { Chuvosa }\end{array}$ & $\begin{array}{c}\text { Est. } \\
\text { Seca }\end{array}$ & $\begin{array}{c}\text { Est. } \\
\text { Chuvosa }\end{array}$ & $\begin{array}{c}\text { Est. } \\
\text { Seca }\end{array}$ \\
P1 & 0,068 & 0,051 & 1,221 & 1,126 & 0,1539 & 0,1858 & 0,055 & 0,051 & 0,083 & 0,081 & 0,2368 & 0,2125 \\
P2 & 10,08 & 10 & 0,41 & 0,38 & 64 & 63,25 & 12,02 & 12 & 20,38 & 20,25 & 9,87 & 9,5 \\
P3 & 6,21 & 6,13 & 1,01 & 1 & 49,01 & 38,75 & 6,35 & 6 & 11,16 & 11,13 & 6,77 & 6,68 \\
P4 & 6,73 & 6,63 & 0,002 & 0 & 28,69 & 28,63 & 11,98 & 11,88 & 25,99 & 25,75 & 9,88 & 9,38 \\
P5 & 4,79 & 4,63 & 0,001 & 0 & 16,58 & 16,38 & 2,55 & 2,38 & 9,58 & 9,38 & 4,81 & 4,75 \\
P6 & 11,28 & 11 & 0,001 & 0 & 17,99 & 17,38 & 8,98 & 8,75 & 12,18 & 12,13 & 9,49 & 9,38 \\
P7 & 9,18 & 9,13 & 0,29 & 0,25 & 15,77 & 15,63 & 6,77 & 6,63 & 12,19 & 12,13 & 9,48 & 9,38 \\
P8 & 11,81 & 11,25 & 0 & 0 & 18,89 & 18,75 & 9,68 & 9,38 & 16,98 & 16,88 & 13,08 & 13 \\
P9 & 11,01 & 10,5 & 0 & 0 & 20,77 & 20,5 & 9,66 & 9,63 & 14,01 & 14 & 12,7 & 12,63 \\
P10 & 10,99 & 10,63 & 0,01 & 0 & 14,18 & 14 & 5,78 & 5,63 & 12,39 & 12,38 & 10,5 & 10,38 \\
P11 & 12,87 & 12,75 & 0,012 & 0,012 & 21,21 & 21 & 10,18 & 10,13 & 15,59 & 15,5 & 11,79 & 11,75
\end{tabular}

Tabela 3 - Em vermelho, os teores e os metais que violaram os valores de referência CONAMA 344/04.

TABELA 3 - VALORES TOTAIS DOS METAIS ANALISADOS - ESTAÇÃO CHUVOSA E SECA

Tabela 3 - Em vermelho, os teores e os metais que violaram os valores de referência-CONAMA 344/04.

de $0,1858 \mathrm{mg} / \mathrm{kg}$ e máximo de $63,25 \mathrm{mg} / \mathrm{kg}$, na estação seca. Nota-se um discreto aumento nos valores de $\mathrm{Cr}$ na estação chuvosa, devido ao carreamento, através das águas pluviais, de material pedológico contendo resíduos metalorgânicos, disponíveis nas áreas agricultáveis. Os pontos P2 e P3 alcançaram valores acima do recomendado pela Resolução CONAMA 344/04 - diante dos dados obtidos, pode-se afirmar que houve contaminação nos sedimentos de corrente para cromo. Esses pontos localizam-se no compartimento geomorfológico Unidades de Chapadas (cujo uso do solo é destinado à agricultura comercial). Ressalta-se que o ponto P2: $64,00 \mathrm{mg} / \mathrm{kg}$ apresentou um aumento significativo de mais de $69 \%$ em relação ao valor de referência TEL, que é de $37,3 \mathrm{mg} / \mathrm{kg}$. Em relação aos pontos $\mathrm{P} 4$ a $\mathrm{P} 11$, os teores de $\mathrm{Cr}$ se encontram abaixo do valor de referência, não havendo até o presente momento, descumprimento da legislação. $\mathrm{O}$ aumento apresentado nos teores totais de $\mathrm{Cr}$ nos sedimentos de corrente pode estar associado a sua utilização como agente ativo das tintas, que são utilizadas na preservação do madeirame, empregado na construção de cercas, galpões e nas casas. Além disso, a intensa utilização de agroquímicos contendo anidrito crômico, ácido crômico, óxido crômico e trióxido de cromo, utilizados no plantio de grãos. Os resíduos metalorgânicos secos e/ou pulverizados são transportados pelo ar e pela água de irrigação e depositados nos solos, quando são disponibilizados para a água superficial e para os sedimentos de corrente. Os pontos que apresentaram alterações em relação os teores totais de $\mathrm{Cr}$ e $\mathrm{Cd}$ deverão ser monitorados com atenção, pois, se encontram localizados em áreas, ambientalmente vulneráveis.

\section{CONCLUSÕES}

A partir dos dados acima expostos, pode-se concluir que os metais pesados $\mathrm{Cd} \mathrm{e} \mathrm{Cr}$, ultrapassaram os valores de referência da Resolução CONAMA 344/2004, comprometendo os compartimentos água e sedimentos. Para os outros elementos, as concentrações encontramse dentro do limite preconizado por essa resolução, entretanto, demandam atenção especial, pois para esses metais os níveis de concentração em alguns pontos encontram-se próximos aos limites recomendados.

A disponibilidade de $\mathrm{Cd}$ e $\mathrm{Cr}$ no compartimento sedimento, é resultado direto dos resíduos metalorgânicos gerados pela agricultura comercial. Os valores de $\mathrm{Cr}$ presentes nos litotipos argilitos, contribuem no enriquecimento desse metal para os sedimentos, disponibilizando-o no meio aquático.

A fração fina dos sedimentos foi a mais propícia, no que se refere aos carreadores geoquímicos ativos, principalmente os de origem antrópica e natural.

Constatou-se a predominância do mineral quartzo, a presença de minerais de argila, como a caolinita, sugere que em alguns pontos amostrados pode ocorrer maior ou menor troca de elementos do sedimento para a coluna de água.

As características morfológicas do canal fluvial 
e a hidrodinânica da bacia funcionaram como um importante mecanismo para a distribuição e transporte dos metais junto aos sedimentos.

Diante dos resultados físicos e químicos apresentados para os sedimentos de corrente e fundo, sugere-se a implantação de um programa de monitoramento para todos os metais pesados analisados.

\section{AGRADECIMENTOS}

Agradecemos o apoio logístico e financeiro das seguintes instituições:

UFMG/IGC/CPMTC, UNIMONTES, CDTN/ CNEN e da FAPEMIG e, a todos que de certa forma contribuíram para a execução deste trabalho.

\section{REFERÊNCIAS BIBLIOGRÁFICAS}

ALlOWAY, B. J. \& AYRES, D. C. 1997. Chemical Principles of Environmental Pollution, 2 ed. Ed. Chapman \& Hall, New York.

BAGGIO, H. F. 2008. Contribuições naturais e antropogênicas para a concentração e distribuição de metais pesados em sedimento de corrente na bacia do Rio do Formoso, município de Buritizeiro - MG. Tese (Doutorado em Geologia). Instituto de Geociências - Universidade Federal de Minas Gerais - UFMG. Belo Horizonte.

BOWEN, J. M H. 1979. Environmental Chemistry of the Elements. London, Academies Press, 1979, 273 p.

BRAGA, L. L. 2007. Avaliação do Impacto Ambiental de um Beneficiamento de Fe e Si, Várzea da Palma, MG, Brasil Distribuição e Transporte dos Contaminantes. 2007. 81 p. Dissertação (Mestrado em Geologia). Instituto de Geociências - Universidade Federal de Minas Gerais - UFMG. Belo Horizonte.

CETEC - Fundação Centro Tecnológico De Minas Gerais. 1980. Estudo de Metais Pesados no Estado de Minas Gerais. Relatório
Final. Belo Horizonte. $151 \mathrm{p}$.

CDTN/CNEN - Centro de Desenvolvimento da Tecnologia Nuclear. 2008.

CONAMA, 2004. Conselho Nacional do Meio Ambiente - Resolução CONAMA n ${ }^{\circ} 344$, de 25 de março de 2004. Disponível em

http://www.mma.gov.br/conama

LUNDHAMER, S. 1991. Erfassung der Kontamination an Metallen im Flusswasser des São Francisco bei Três Marias, Brasilien. Tese de Diploma, Fachhochschule München, inédito: 74 p.

MOZETO, A. A. 2003. Diagnóstico Preliminar de Contaminação Ambiental por Metais na Área de Influência da VM na Bacia do Rio São Francisco, Região de Três Marias (MG). Laboratório de Biogeoquímica Ambiental - DQ - UFSCar/ São Carlos, SP.

OLIVEIRA, R. M. 2007. Investigação da Contaminação por Metais Pesados da Água e do Sedimento de Corrente nas Margens do Rio São Francisco e Tributários, a Jusante da CEMIG, no Município de Três Marias-MG. 149 p. Dissertação (Doutorado em Geologia). Instituto de Geociências - Universidade Federal de Minas Gerais - UFMG. Belo Horizonte.

RIBEIRO, E. V. 2007. Níveis de contaminação por metais pesados em águas superficiais do Rio São Francisco em Pirapora e sua relação com as atividades industriais. 2007. 101 p. (Monografia) - Departamento de Geografia. Universidade Estadual de Montes Claros - UNIMONTES. Minas Gerais.

KRAUSKOPF, K, B. 1976. Introduction to geochemistry. New York, McGraw-Hill. 721 p.

MUNSELL SOIL COLOR CHARTS. 2000. Little Britain Road, New Windsor, NY. Washable Edition New York.

SEER, H. J.; MORAES, L. C. DE; FOGAÇA, A. C. C. 1989. Roteiro Geológico para a Região de Lagoa Formosa-Chumbo-Carmo do Paraíba-MG. 58 p. (Boletim SBG-MG, n. 9).

SGARBI, G. N. C. 1989. Geologia da Formação Areado, Cretáceo Médio a Inferior da Bacia do São Francisco, oeste do Estado de Minas Gerais. 1989. 324 p. Dissertação (Mestrado) - Inst. de Geociências, Universidade Federal do Rio de Janeiro - UFRJ. Rio de Janeiro.

VIANA, V. M. F. C. 2006. Estudo Geológico Ambiental das Veredas do Rio do Formoso no Município de Buritizeiro-MG. 2006. 71 p. Dissertação (Mestrado em Geologia)-Instituto de Geociências - Universidade Federal de Minas Gerais - UFMG. Belo Horizonte. 